\title{
The features of socio-communicative and environmental competence of youth
}

\author{
Natalia Filina ${ }^{1, *}$, Irina Akhmetshina ${ }^{2}$, Dmitrii Soldatov ${ }^{2}$, and Raniya Izmaylova ${ }^{2}$ \\ ${ }^{1}$ Russian State Social University, 129226, Wilhelm Pieck street, 4, build.1, Moscow, Russia \\ ${ }^{2}$ State University of Humanities and Technology, 142600, Zelenaya street, 22, Moscow Region, \\ Orekhovo-Zuevo, Russia
}

\begin{abstract}
The study of the orphans' communicative competence is a topical thing. The situation of the orphanhood disrupting the function of communication, affects the subsequent development of the child, hindering his intellectual and personal development, preventing the formation of confidence in the security of the surrounding world, initiative, autonomy and identity. The orphanhood can destroy the children's' emotional connections with the environment, the world of peers and adults, causing the deepest secondary disorders of a mental, physical, and social nature. Method of the theoretical analysis and systematization of scientific ideas, individualtypological questionnaire L. N. Sobchik; method of the research of communicative-characterological tendencies $\mathrm{T}$. Leary; method of expert assessment of the communicative development level A. G. Samokhvalova; method of communicative control research M. Schneider; diagnostics of communicative social competence; diagnostics of "emotional intelligence" $\mathrm{N}$. Hall; and the assessment were used. We identified the neediness of special psychoeducational work for the successful adaptation of the orphans. It will ensure the mastery of a complex of social roles and the formation of communicative competence. The results complement the existing theoretical positions on the problem of the communicative competence of orphans can be used in the correctional psychological work with orphan-graduates.
\end{abstract}

\section{Introduction}

According to the State Statistical Committee of the Russian Federation, there are near 50 thousand children, who do not have parental care. The bulk are not orphans, but children whose parents refused to raise or were deprived of the parental rights. Nowadays, they are 37966 children. In 2019, the percentage of orphans and children who left without parental care, who are brought up in residential institutions increased from $87,3 \%$ till $89,02 \%$. The main reasons, which contribute to the widespread prevalence of social orphanhood, are the social disorganization of families, housing and financial difficulties of parents, unpleasant relationships between them, weaknesses in the moral structure of most families, as well as an increasing number of children born out of wedlock.

\footnotetext{
${ }^{*}$ Corresponding author: sinebroffka2005@gmail.com
} 
The studies of S.I. Hairova [1], M. Daniel and A. Mathias [2] prove that the problem of communication difficulties is typical for the graduates of residential institutions. The difficulties in the building effective communication leads to the development of failure in achieving the goal, dissatisfaction with the motives, as well as the failure in achieving the desired result, which negatively affects on the ego and the personal development of graduates of residential institutions. The study of the graduates of residential institutions' communicative competence is a topical question, in conditions of the successful adaptation and socialization. The position of the psychologist exists in Russian residential institutions and orphanages more than 20 ages. It is to ensure the full personal development of children who do not have a family and provide them with highly qualified psychological assistance.

The socio-psychological features of the personality of orphans are considered in the works of domestic and foreign scientists: V.A. Abelbejsov [3], V.A. Kapustina [4], S.N. Majorova-SHCHeglova, E.A. Kolosova [5], D. Cable, J.J. Lee, F. Gino, B.R. Staats [6], A.G. La Valley, L.K. Guerrero [7], J.S. Yendork, N.Z. Somhlaba [8] etc.

The problem of the formation of communicative competence in orphans is reflected in the researches of I.A. Grigoreva [9], S.I. Levikov [10], M.A. Patrin, T.A. Novohackaya, I.S. Grigor'ev, G.A. Revazyan [11], S. Ali, A. Khaleque, R.P. Rohner [12], L.I. Bordonaro [13], G. Bouchard [14], E. Cohen [15], E. Ganga, M.C. Maphalala [16], R. Stryker [17], M. Thamuku, M. Daniel [18], N. Xu [19] etc.

The theoretical analysis of the domestic and foreign scientific literature showed that the communicative competence of the orphans is connected with the individual-personal properties and processes of social development. That's why the development of the communicative competence is a purposeful set of measures that should be focused on the development of laws, norms, and principles of communicative behavior in orphans, based on patterns, values, ideals, and traditions that are positive criteria for the life of society in a certain period of development. The formation of the communicative competence of the personality is very important for the implementation of adaptation, self-realization of the personality, which is included in the concept of "communication". A communication, as an action, realizes the informational, factual and emotional function, and it is a meaningful act of social interaction. The spread of orphanhood in Russia is due to the influence of social "diseases" of society: alcoholism, drug addiction, immoral lifestyle, high level of poverty, and etc. It is very difficult to name all the reasons of the orphanhood, because it is a multidimensional problem. However, we can highlight 3 main problems, leading to the spread of the phenomenon: voluntary abandonment of the child by the parents, forced removal of the child, death of the parents.

The formation of the communicative competence of graduates of residential institutions and children who do not have parental care is the condition of adaptation and socialization of the personality. The characteristic of the communicative competence of the orphans, who are preparing for graduation from a residential institution is low level of communication, difficulties in establishing contacts, self-doubt, low self-esteem, anxiety, lack of friends, low level of emotional and volitional regulation, lack of goal-setting skills, low indicators of social activity and a low level of the empathy and sensitivity development. Therefore, the main task of the psychoeducational work with the graduates of the residential institutions is an assistance to the future graduate in the development of self-improvement, selfunderstanding, orientation to the awareness of their own uniqueness, creating awareness of the values of communication. The formation of the communicative competence of the orphans occurs spontaneously in most cases, that's why the insufficient personal readiness for the processes of interaction with people is a weak aspect of the social characteristics of the orphans. 


\section{Materials and methods}

We made a skilled-experimental work based on GKOU « Sem'ya i dom » in Orekhovo-Zuevo of the Moscow region for the orphans and children left without parental care. The sample consisted of 25 people. The study involved 13 boys and 12 girls, including 6 children aged 13-14 years, 10 children aged 14-15 years, 9 children aged 15-16 years. During the study we used the method of the theoretical analysis and systematization of scientific ideas, individualtypological questionnaire L. N. Sobchik; method of the research of communicativecharacterological tendencies $\mathrm{T}$. Leary; method of expert assessment of the level of communicative development of the child A. G. Samokhvalova; method of the research of communicative control M. Schneider; diagnostics of communicative social competence; diagnostics of "emotional intelligence" N. Hall; quantitative and qualitative assessment of the obtained results.

\section{Results}

Let's consider the content and results of the diagnostic work. We used the method of the research of communicative-characterological tendencies $\mathrm{T}$. Leary for the determination the severity of such types of interpersonal relationships (authoritarian, egoistic, aggressive, suspicious, subordinate, dependent, benevolent, altruistic) and the social orientations of the personality. The results are presented in Figure 1.

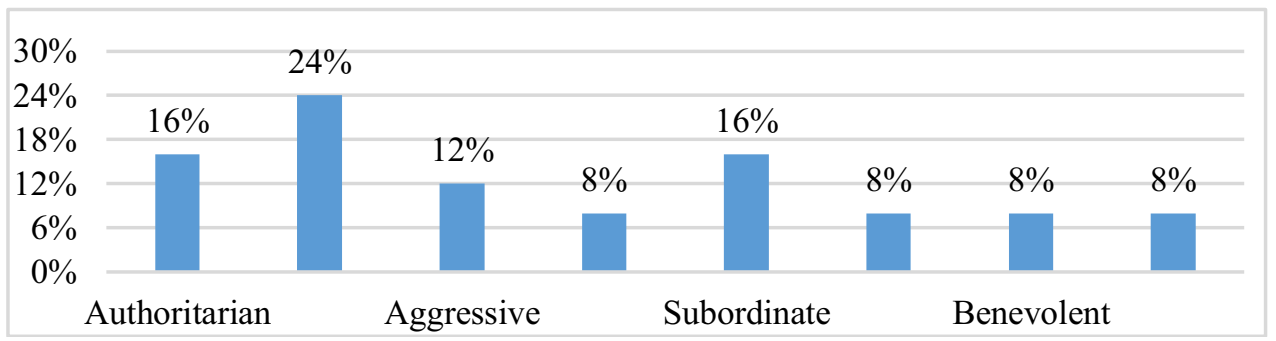

Fig. 1. The ratio of indicators of the prevailing type of relationships between adolescents and others.

As we can see, the relevant type of the interpersonal relationships in the studying orphans' group is egoistic type, 6 adolescents $(24 \%)$ demonstrated it. These teenagers are characterized by the desire for predominance, prudence, independence, narcissism. These children shift the responsibilities on the others, showing the boasting and arrogance. It is extremely difficult for them, to build a harmonious relationship.

The dominating types of relationships between teenagers and others are authoritarian, 4 people $(16 \%)$ and subordinate, 4 people (16\%). Orphaned adolescents who exhibit an authoritarian type of relationship are characterized by dominance, energy, and authority in building relationships, while the subordinate type is characterized by compliance, emotional restraint, and the ability to obey others. These adolescents rarely express their own opinion on this or that occasion, do not contradict the opinion of others, easily fall under the influence (sometimes negative) of others.

The aggressive type of relationships between teenagers was detected in 3 adolescents $(12 \%)$. The frankness, exactingness, strictness, straightforwardness is typical for this type. 2 people $(8 \%)$ have such types or the interpersonal relationships like suspicion (hostile and alienated attitude towards social interaction), 2 people $(8 \%)$ have dependence (docility, fearfulness), 2 people ( $8 \%$ ) have benevolence and $2(8 \%)$ have altruism (the tendency of cooperation, the desire to serve people). We used method of expert assessment of the level 
of communicative development of the child A. G. Samokhvalova for the study of communication difficulties in adolescents with peers and adults (Figure 2).

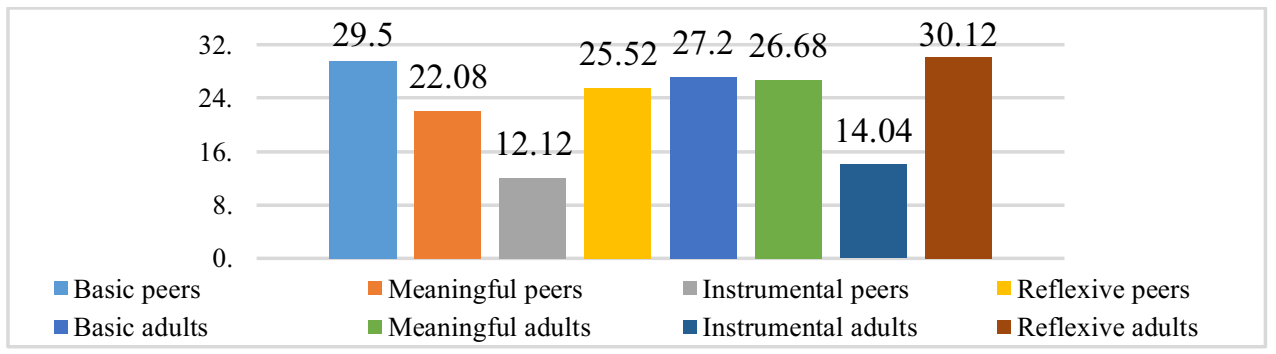

Fig. 2. The results of the average values of the study of communication difficulties of adolescents in relationships with adults and peers.

As we can see on the picture 2, the nature of the existing communication difficulties with peers and adults in the studied orphaned adolescents differs. In the conditions of the study of the communicational difficulties the basic (29.5) and reflexive (25.52) difficulties predominate, the informative (22.08) difficulties are further, the instrumental ones (12.12) are practically not expressed. As for communication difficulties with adults, the studied orphan adolescents are dominated by reflexive (30.2), basic (27.2) and meaningful (26.68) ones. They are almost expressed at the same level, the lowest is instrumental (14.04), but the indicator is higher than the same with peers.

We can make a conclusion that the main difficulties in the communication with peers are the egocentrism, irritability, difficulties in empathy, difficulties in establishing contact, manifestation of envious tendencies, lack of initiative.

The adolescents have the difficulties in the process of the communication. These difficulties create the obstacles to the adequate analysis and evaluation of their own communicative actions by orphaned adolescents, blocking the aspirations for selfdevelopment, accompanied by difficulties in self-analysis of communicative actions, difficulties in self-understanding feelings, lack of formed skill to analyze their own mistakes, difficulties in understanding the partner.

We have studied the level of the communicational control using the method of $\mathrm{M}$. Schneider (Figure 3).

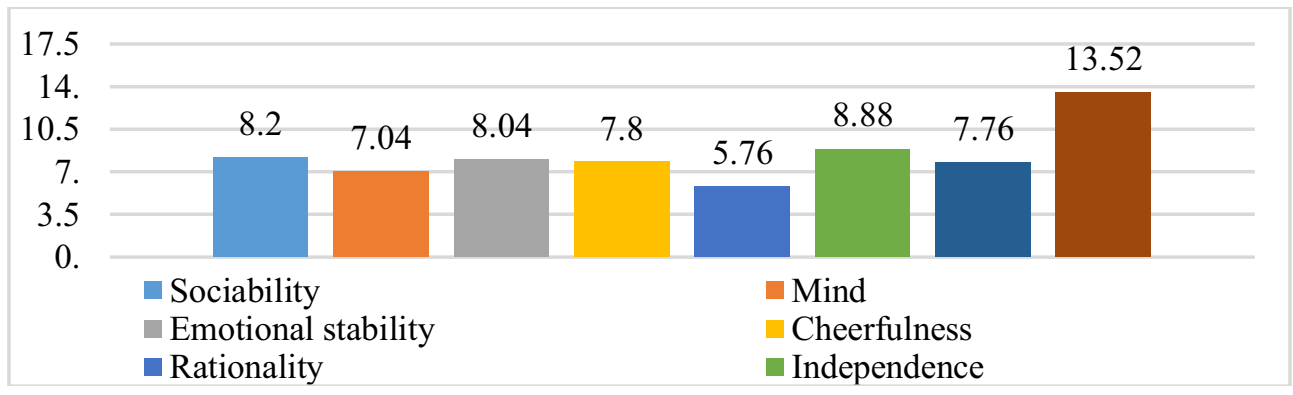

Fig. 3. The components of social and communicative competence of the adolescents.

The results shows that for the pupils of residential institutions, namely the group of orphaned teenagers under study, or teenagers left without parental care, the following characteristics are typical:

- the absence of a tendency to increased sociability, but at the same time, the absence of a tendency to isolation $(8,2)$;

- an inattention, reduced level of logical thinking formation (7.04); 
- there is a certain ambivalence in the indicators of emotional stability, which reflects the rationality of the manifestation of the feelings and emotions in the interaction situation $(8,04)$;

- the lightness, cheerfulness, predominance of a positive mood, sobriety and taciturnity are more likely to be observed $(7,8)$;

- the rationality and self-confidence $(5,6)$;

- the desire for independence and free thinking with a preserved tendency of dependence on the group $(8,8)$;

- impulsivity, disorganization $(7,76)$;

- a tendency to deviant behavior $(13,52)$.

The diagnostic of the communicational social competence (CSC) let us to determine the severity of the components of social and communicative competence (sociability, thinking, emotional stability, cheerfulness, rationality, independence, self-control, tendency to deviant behavior) in adolescents (Figure 4).

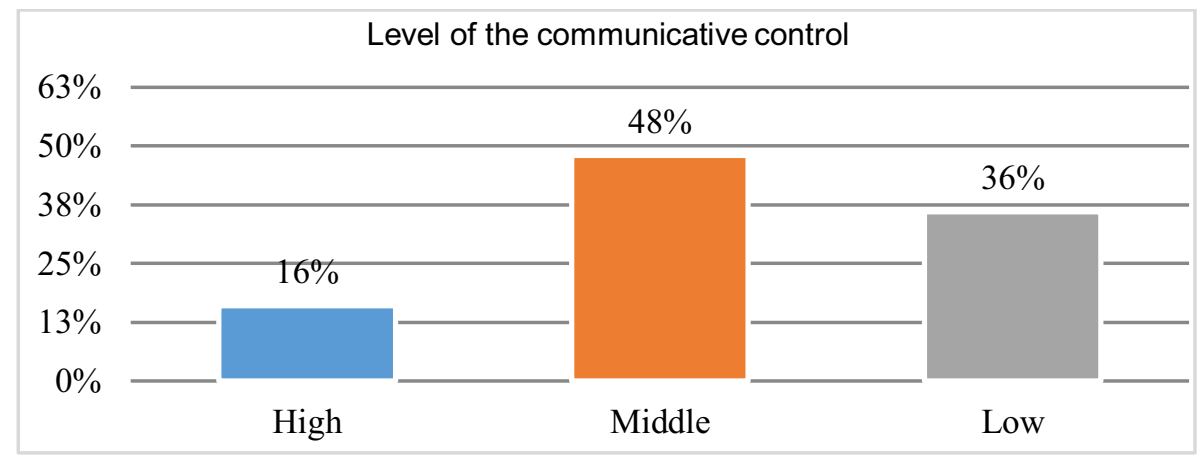

Fig. 4. Levels of the communicative control of adolescents.

The results shows that the predominant level of communication control among the studied orphaned adolescents is average, which 12 people (48\%) showed. 4 adolescents $(16 \%)$ showed the low level of the communicational control, 4 adolescents $(16 \%)$ showed the high level.

On this basis, we conclude, that the spontaneity in communication, lack of restraint regarding emotional manifestations and the presence of impulsive tendencies are typical for orphaned teenagers.

Emotional intellect is an important part of the communicative competition that is why we used the method of N. Hall for the studying the features of this phenomenon among the group of the orphans (Figure 5).

The comparative analysis of the results shows that the low level of emotional intelligence prevails in the study group of orphaned adolescents; it was defined in 15 people $(60 \%) .7$ adolescents have the middle level (28\%), 3 adolescents have the high level (12\%) (Figure 6).

Analyzing the average values for the components of emotional intelligence in adolescents, we got the lowest values for the "empathy" component (6.88) and "ability to manage emotions" (7.24). At a high level, adolescents formed the components «emotional awareness " $(8,4)$," self-motivation " $(8,36)$ and skills for recognizing the emotions of other people $(8,28)$. 


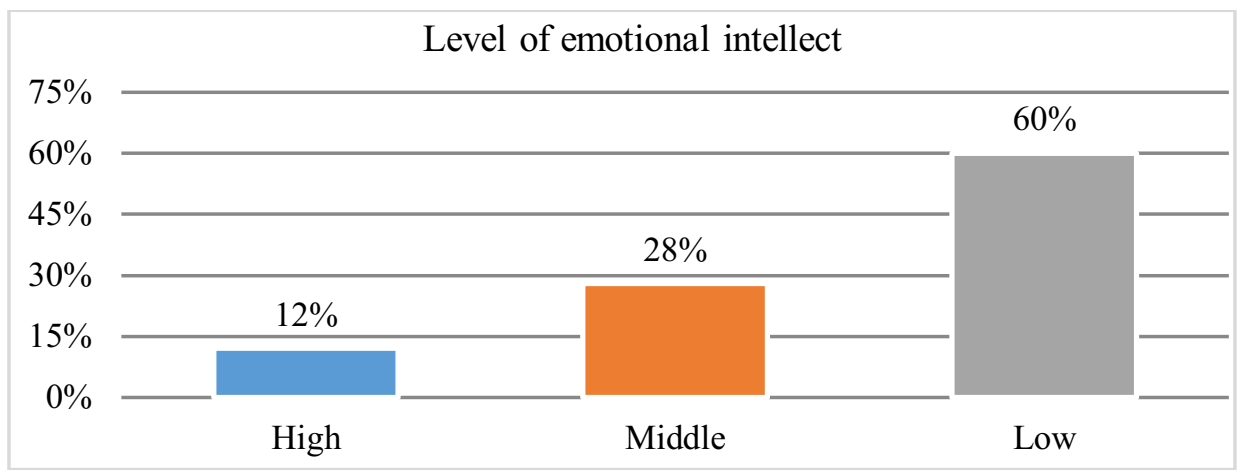

Fig. 5. Levels of the emotional intelligence formation of adolescents.

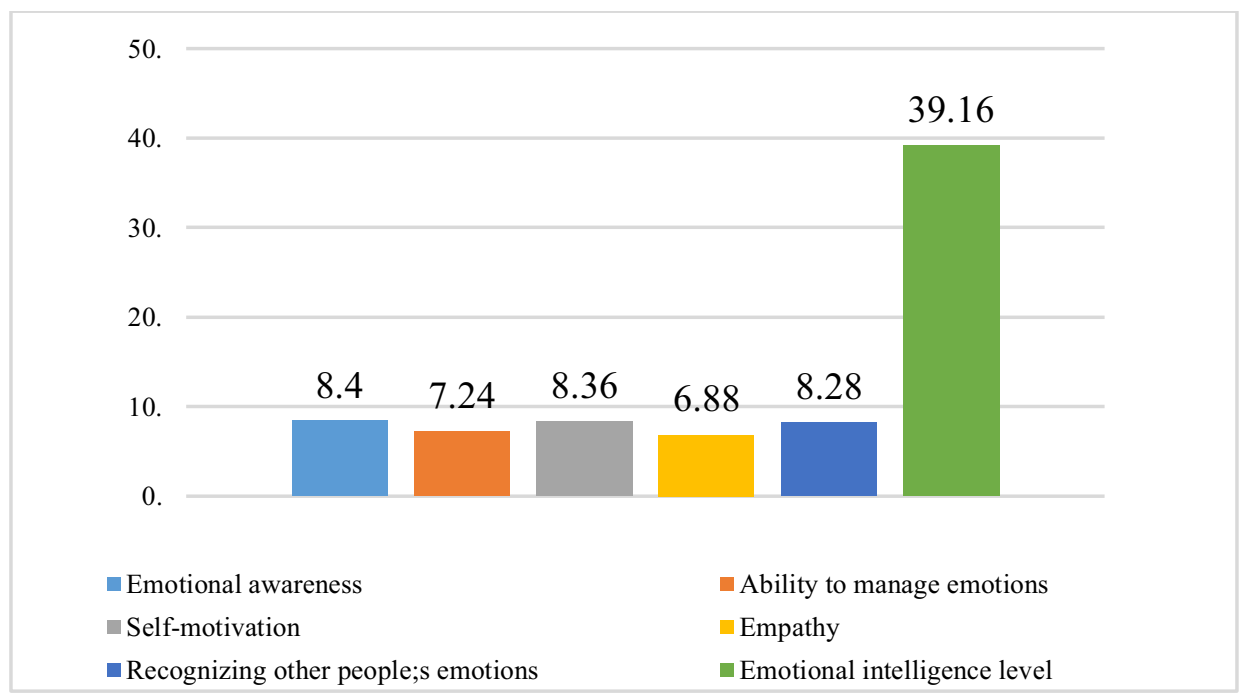

Fig. 6. The components of emotional intelligence of the adolescent.

To determine the severity of individual and typological characteristics of the personality of adolescents, we used a questionnaire by L. N. Sobchik (Figure 7).

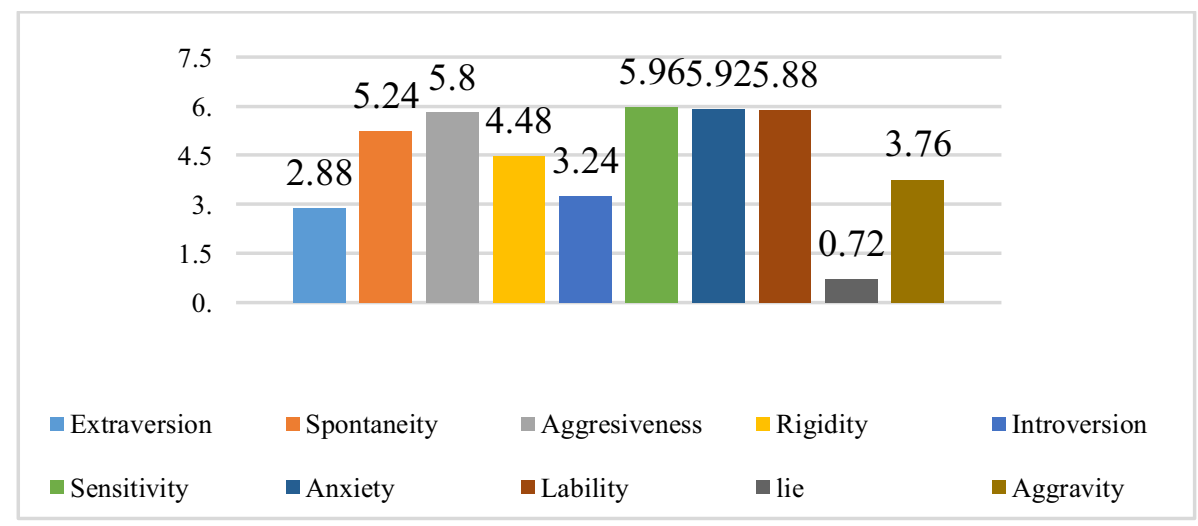

Fig. 7. The individual-typological features of the adolescents. 


\section{Discussion}

Based on the results of a comparative analysis we can point the lack of pronounced accentuated indicators that would have a negative impact on the difficulties of social adaptation and cause psychoemotional disorders in the orphaned teenagers. Besides, the most pronounced typological properties of the group of orphaned adolescents are increased sensitivity (5.96), anxiety (5.92), lability (5.88), aggressiveness (5.8). Spontaneity (5.24), rigidity (4.48), aggravity (3.76), introversion (3.24), extraversion (2.88) are on the middle level. The tendency of adolescents to lie is on the low level $(0.72)$.

\section{Conclusions}

Because of the conducted empirical research, we identified the features of the communicative competence of graduates of educational institutions for orphans, as well as children left without parental care on the example of a group of orphaned adolescents. The egoistic type of orientation in interpersonal relationships, as well as interpersonal interaction predominates in the group of adolescents. The determinants of this orientation in the construction of interpersonal relationships, as determined by the use of other methods, are the difficulties in the building of communicational contacts, which have the different orientation, depending on the subject of communication: adults or peers. The orphaned adolescents have the difficulties in the development of difficulties in building communication with peers. They are determined by personal qualities that prevent teenagers from effectively solving communication problems, namely: egocentrism, irritability, difficulties in empathy, difficulties in establishing contact, the manifestation of envious tendencies, and lack of initiative. The communicative competence of the adolescents is due to the prevailing average level of communicative control, the presence of emotional barriers in communication because their emotional intelligence is developed at a low level. It is manifested in the lack of developed skills of awareness and understanding of emotions, emotional rigidity, low level of empathy, empathy skills and understanding of interaction partners.

All of the named components of communicative competency can be determinate by a set of individual and typological characteristics of the personality of adolescents. They are characterized by the severity of ill-considered actions and statements, stubbornness, inertia of attitudes, criticality, a tendency to introversion, reflection, impressionability, insecurity, emotionality, anxiety, constant changes in the emotional state and changes in motivational orientation.

\section{References}

1. S.I. Hairova, Features of interpersonal relations of adolescents with different sociometric status, Soviet science: actual problems of theory and practice. Series: Cognition 12, 136142 (2020) DOI: https://doi.org/10.37882/2500-3682.2020.12.36

2. M. Daniel, A. Mathias, Challenges and coping strategies of orphaned children in Tanzania who are not adequately cared for by adults, African Journal of AIDS Research 11, 3, 191-201 (2012) DOI: https://doi.org/10.2989/16085906.2012.734978

3. V.A. Abelbejsov, Orphans and children left without parental care in modern Russia, Politicas and Society 9, 1109-1113 (2013) DOI: https://doi.org/10.7256/18128696.2013.9.5093

4. V.A. Kapustina, Socio-psychological determinants of the process of socialization of adolescents from full and incomplete families, Psychologist 1, 16-26 (2017) DOI: https://doi.org/10.7256/2409-8701.2017.1.21093 
5. S.N. Majorova-Shcheglova, E.A. Kolosova, Children and childhood as objects of sociological research, Sociological research 3, 62-69 (2018) DOI: https://doi.org/10.7868/s0132162518030066cable

6. A.G. La Valley, L.K. Guerrero, Perceptions of conflict behavior and relational satisfaction in adult parent-child relationships: A dyadic analysis from an attachment perspective, Communication Research 39, 1, 48-78 (2012) DOI: https://doi.org/10.1177/0093650210391655

7. J.S. Yendork, N.Z. Somhlaba, Problems, Coping, and Efficacy: An Exploration of Subjective Distress in Orphans Placed in Ghanaian Orphanages, Journal of Loss and Trauma 20, 6, 509-525 (2015) DOI: https://doi.org/10.1080/15325024.2014.949160

8. I.A. Grigor'eva, Children as subjects of their well-being and social participation, Journal of Social Policy Research 17 (4), 668-673 (2019) DOI: https://doi.org/10.17323/7270634-2019-17-4-668-673

9. S.I. Levikova, Features of socialization of modern Russian teenagers as one of the factors of social dynamics, Sociodynamics 6, 1-11 (2017) DOI: https://doi.org/10.25136/2409-7144.2017.6.22453

10. M.A. Patrin, T.A. Novohackaya, I.S. Grigorev, G.A. Revazyan, Possibilities of solving the problems of socialization of orphans with the help of information resources, Vestnik RUDN. Series: Informatics of Education 16, 2, 185-193 (2019) DOI: https://doi.org/10.22363/2312-8631-2019-16-2-185-193

11. S. Ali, A. Khaleque, R.P. Rohner, Pancultural. Gender Differences in the Relation Between Perceived Parental Acceptance and Psychological Adjustment of Children and Adult Offspring: A Meta-Analytic Review of Worldwide Research, Journal of Cross-Cultural Psychology 46, 8, 1059-1080 (2015) DOI: https://doi.org/0.1177/0022022115597754

12. L.I. Bordonaro, Agency Does Not Mean Freedom. Cape Verdean Street Children and the Politics of Children's Agency, Children's Geographies 10 (4), 413-426 (2012) DOI: https://doi.org/10.1080/14733285.2012.726068

13. G. Bouchard, How Do Parents React When Their Children Leave Home? An Integrative Review, Journal of Adult Development 21, 2,69-79 (2014) DOI: https://doi.org/10.1007/s10804-013-9180-8

14. E. Cohen, The Orphaned Children, Folklore 43, 2, 210-216 (2012) DOI: https://doi.org/10.1080/0015587X.1932.9718440

15. E. Ganga, M.C. Maphalala, Cognitive Learning: A Life-line Challenge for Orphans and Vulnerable Children in Child-headed Households, Journal of Social Sciences 36, 1, 4958 (2013) DOI: https://doi.org/10.1080/09718923.2013.11893172

16. R. Stryker, Emotion Socialisation and Attachment in Russian Children's Homes, Global Studies of Childhood 2, 85-96 (2012) DOI: https://doi.org/10.2304/gsch.2012.2.2.85

17. M. Thamuku, M. Daniel, Exploring Responses to Transformative Group Therapy for Orphaned Children in the Context of Mass Orphaning in Botswana, Death Studies 37, 5, 413-447 (2013) DOI: https://doi.org/10.1080/07481187.2012.654594

18. N. Xu, Caring for orphaned children in China, Disability \& Society 29, 9, 1501-1503 (2014) DOI: https://doi.org/10.1080/09687599.2014.931649 